DOI: $10.29184 / 1980-7813 . r c f m c .188 . v o l .12 . n 3.2017$

\title{
ANÁLISE DOS ASPECTOS CLÍNICOS E MANEJO DA INFECÇÃO PELO VÍRUS CHIKUNGUNYA
}

\author{
ANALYSIS OF CLINICALASPECTS AND MANAGEMENT OF \\ CHIKUNGUNYA VIRUS INFECTION
}

\author{
João de Azevedo ${ }^{1}$, Paola de Araujo Sardenberg Alves ${ }^{1}$ \\ ${ }^{1}$ Acadêmico da Faculdade de Medicina de Campos, 28035-581, Campos dos Goytacazes, RJ, Brasil.
}

\section{RESUMO}

A febre Chikungunya é uma arbovirose causada pelo vírus Chikungunya (CHIKV), um vírus enzoótico de RNA pertencente à família Togaviridae e ao gênero Alphavirus, encontrado principalmente em regiões tropicais e subtropicais da Africa, nas ilhas do Oceano Índico, no Sul e Sudeste da Ásia.Foi isolado pela primeira vez em 1952, na Tanzânia. Seu nome significa "andar encurvado".Sua transmissão ocorre pela picada de fêmea dos mosquitos Ae. Aegypti e Ae. Albopictus infectados pelo CHIKV, possuindo um período de incubação no ser humano de, em média, 3 a 7 dias, podendo variar de 1 a 12 dias e período de viremia de até dez dias após o surgimento das manifestações clínicas. A infecção leva a formas sintomáticas em até $70 \%$ dos infectados, sendo suas formas clínicas, nos pacientes sintomáticos, divididas em três fases: aguda ou febril, com duração de até dez dias; subaguda, que dura até três meses; e crônica, a qual pode chegar a anos. Para que haja um correto manejo clínico de cada fase da doença, bem como um diagnóstico precoce a fim de evitar a evolução para formas incapacitantes, é de suma importância o conhecimento das manifestações dessa arbovirose e como conduzila na sua evolução.

Palavras-chave:Chikungunya, arbovirose, Aedes Aegypti, artralgia, manejo clínico

\begin{abstract}
Chikungunya fever is an arboviral disease caused by the Chikungunya virus (CHIKV), an enzootic RNA virus belonging to the Togaviridae family and the Alphavirus genus, found mainly in tropical and subtropical regions of Africa, in the Indian Ocean, South and Southeast Asia It was first isolated in 1952 in Tanzania. Her name means "bent walking." Her transmission occurs through the female bite of mosquitoes Ae. Aegypti and Ae. Albopictus infected with CHIKV, having an incubation period in humans of, on average, 3 to 7 days, ranging from 1 to 12 days and a viremia period of up to 10 days after the appearance of clinical manifestations. Infection leads to symptomatic forms in up to $70 \%$ of those infected, and their clinical forms in symptomatic patients are divided into three phases: acute or febrile, lasting up to ten days; Subacute, which lasts up to three months; And chronic, which can reach years. For a correct clinical management of each stage of the disease, as well as an early diagnosis in order to avoid the evolution to incapacitating forms, the knowledge of the manifestations of this arbovirosis and how to conduct it in its evolution is of paramount importance
\end{abstract}

Key words: Chikungunya, arbovirose, Aedes Aegypti, arthralgia, clinical management. 


\section{INTRODUÇÃO}

A febre Chikungunya é uma arbovirose causada pelo vírus Chikungunya (CHIKV). O CHIKVé transmitido pela picada da fêmea dos mosquitos Ae. Aegypti e Ae. Albopictus. Existem três formas clinicas da doença, com sintomas predominantes diferentes e suas próprias peculiaridades, tendo porém um destaque para a forma crônica, que possui uma alta taxa de morbidade.

Sabe-se hoje, que afebre Chikungunya é um dos principais diagnósticos diferenciais da Dengue e da ZIka na atualidade, uma vez que seus sinais e sintomas são bem similares. Essa revisão bibliográfica tem como objetivo atualizar e destacar o importante papel desta arbovirose, que vem se difundindo pelo país, desde sua epidemiologia ao tratamento preconizado, para que se possa reconhecer e diagnosticar de forma precoce a infecção pelo vírus Chikungunya, evitando a mortalidade e as importantes morbidades dessa enfermidade.

\section{REVISÃO BIBLIOGRÁFICA - CHIKUNGUNYA}

\section{EPIDEMIOLOGIA}

A febre Chikungunya é uma arbovirose causada pelo vírus Chikungunya (CHIKV), um vírus enzoótico de RNA pertencente à família Togaviridae e ao gênero Alphavirus, encontrado principalmente em regiões tropicais e subtropicais da Africa, nas ilhas do Oceano Índico, no Sul e Sudeste da Ásia. ${ }^{1} \mathrm{O}$ CHIKV foi inicialmente isolado na Tanzânia por volta de 1952, de onde veio a origem do nome Chikungunya. Proveniente de uma palavra em Makonde, uma língua falada por um grupo que vive no sudeste da Tanzânia e norte de Moçambique, significa "aqueles que se dobram", fazendo uma referência à característica posição daqueles que sofrem da artralgia causada pelo vírus. A partir do ano de 2013, o CHIKV se estabeleceu nas Américas com início de uma epidemia em diversas ilhas do Caribe. ${ }^{2,3}$

Sua transmissão ocorre pela picada de fêmea dos mosquitos Ae. Aegypti e Ae. Albopictus infectados pelo CHIKV, possuindo um período de viremia de até dez dias após o surgimento das manifestações clínicas. Casos de infecção vertical podem ocorrer, e são descritos apenas no momento do parto em gestantes virêmicas, e quando ocorrem, em sua maioria das vezes provoca uma infecção neonatal grave. A transmissão via tranfusional é rara devido aos protocolos para a mesma, mas pode ocorrer em casos de falhas. ${ }^{2,3,4}$
No Brasil, o primeiro caso confirmado foi em setembro de 2014, na cidade de Oiapoque, localizada no Amapá. Durante o restante do ano, ainda foram confirmados outros 2.772 casos de Chikungunya na região Norte (Amapá e Roraima), Nordeste (Bahia), Centro-Oeste (Goiás, Distrito Federal e Mato Grosso do Sul). Hoje em dia esta epidemia vem cada vez mais se espalhando, já havendo casos confirmados em nossa região, sendo assim responsável por uma parcela dos nossos atendimentos ambulatoriais. ${ }^{2,3}$ Essa difusão rápida acontece por alguns motivos demográficos e socioeconômicos de nosso país: a susceptibilidade da população, uma vez que é um novo vírus em circulação no território nacional; a ampla difusão dos vetores responsáveis em transmitir o CHIKV; a grande extensão territorial, dificultando a vigilância e medidas de saúde com finalidade de controle da doença; o alto trânsito da população dentro do país, facilitando a propagação do vírus, uma vez que seu período de viremia é elevado; a circulação mútua do DENV e CHIKV, o que dificulta seu diagnóstico e de forma consequente sua abordagem terapêutica. ${ }^{1}$

\section{MANIFESTAÇÕES CLÍNICAS}

O Chikungunya Vírus (CHIKV) possui período de incubação no ser humano de, em média, 3 a 7 dias, podendo variar de 1 a 12 dias. O período de viremia inicia-se dois dias antes do início dos sintomas e dura por até oito dias após seu aparecimento, ou seja, tem duração total de dez dias, podendo infectar novos mosquitos durante essa fase.

Ao contrário da maioria das arboviroses, nas quais a maior parte dos indivíduos desenvolve infecções assintomáticas, o CHIKV leva a formas sintomáticas em até $70 \%$ dos infectados.

As formas clínicas dos pacientes sintomáticos são divididas em três fases: aguda ou febril, com duração de até dez dias; subaguda, que dura até três meses; e crônica, a qual pode chegar a anos. Casos graves da doença e óbitos ocorrem principalmente em pacientes com comorbidades e extremos de idades. Porém, a letalidade do CHIKV observada até o momento é baixa, inferior a da dengue. ${ }^{1,5}$

\section{FORMAS CLÍNICAS}

\section{- FASE AGUDA OU FEBRIL}

Essa fase é semelhante à dengue e a outras arboviroses. Inicia-se um quadro súbito de febre alta associada a manifestações inespecíficas, como cefaléia, dor retro-orbitária, astenia, mialgia e artralgia. Pode haver conjuntivite, sintomas 
gastrointestinais (mais em crianças), neurite, faringite e linfonodomegalias. Esse quadro dura em média sete dias.

A artralgia é o sintoma mais importante e típico na Chikungunya. A dor é intensa e incapacitante, levando a dificuldade de realizar tarefas simples, como pentear o cabelo, segurar objetos e deambular. Esse sintoma é descrito em pelo menos $90 \%$ dos pacientes, sendo normalmente poliarticular e simétrica, porém pode apresentar assimetria. Acomete pequenas e grandes articulações, predominando em localização distal. Ao exame, observa-se edema articular, caracterizando artrite.

Cerca de metade dos pacientes apresenta exantema macular ou maculopapular, pruriginoso ou não, predominando em tronco e extremidades. Essa manifestação aparece comumente do segundo ao quinto dia após a febre. Dermatologicamente, também são relatados casos de hiperpigmentação, lesões vesicobolhosas, dermatite esfoliativa, eritema nodoso, úlceras orais e fotossensibilidade.

\section{- FASE SUBAGUdA:}

Ocorre o desaparecimento da febre e da maioria dos outros sintomas, com permanência ou exarcebação da artralgia nas regiões previamente acometidas e tenossinovite hipertrófica subaguda em punhos e tornozelos. O paciente não consegue realizar tarefas rotineiras devido à intensa dor. Observa-se edema articular de variável intensidade.

Podem estar presentes também as lesões cutâneas relatadas na fase aguda, surgimento de doença vascular periférica, fadiga e depressão.

A duração da fase subaguda é de três meses desde o início dos sintomas. Passado esse tempo, instala-se a fase crônica.

\section{- FASE CRÔNICA:}

Essa fase é a permanência da artralgia que pode durar até três anos. Atinge cerca de metade dos pacientes com CHIKV e acomete principalmente os com idade acima de 45 anos, com lesão articular preexistente ou alto grau de lesão articular na fase aguda.

A artralgia permanece nas articulações acometidas previamente podendo apresentar, ou não, edema. Existem relatos de dores em regiões sacroilíaca, lombossacra e cervical. Há limitação dos movimentos, deformidades e ausência de eritema. Alguns pacientes podem evoluir com artropatia destrutiva semelhante à artrite psoriática ou reumatóide.
Outros sintomas possíveis são fadiga, cefaleia, prurido, alopecia, exantema, bursite, tenossinovite, disestesias, parestesias, dor neuropática, fenômeno de Raynaud, alterações cerebelares, distúrbios do sono, alterações da memória, déficit de atenção, alterações do humor, turvação visual e depressão. ${ }^{1,5,6}$

\section{DIAGNÓSTICO}

O CHIKV faz diagnóstico diferencial com doenças febris associadas aartralgia. Seu principal diagnóstico diferencial atualmente é a dengue. Além da dengue, também fazem parte do diagnóstico diferencial febre reumática, artrite reumatóide e artrite séptica.Devemos suspeitar e iniciar a investigação diagnóstica para todos os pacientes com febre de início súbito maior que $38,5^{\circ} \mathrm{C}$ e artralgia ou com artrite intensa de início agudo, não explicada por outras condições, sendo residente ou tendo visitado áreas endêmicas ou epidêmicas até duas semanas antes do início dos sintomas ou que tenha vínculo epidemiológico com algum caso confirmado.

A confirmação diagnóstica é feita a partir de isolamento viral, PCR, presença de IgM (coletado durante a fase aguda ou de convalescença), ou aumento de quatro vezes o título de anticorpos demonstrando a soroconversão entre amostras nas fases aguda e convalescente, preferencialmente de 15 a 45 dias após o início dos sintomas, ou 10 a 14 dias após a coleta da amostra na fase aguda. A detecção de anticorpos neutralizantes por meio do teste de neutralização por redução de placas (PRNT) também se mostra como uma opção diagnóstica, e a mesma pode ser conclusiva com a positividade em única amostra de soro.

Vale ressaltar que assim como na Dengue, no curso de uma epidemia, a confirmação pode ser feita através de critério clínico-epidemiológico, reservando a investigação laboratorial para os casos graves ou com as manifestações atípicas, exceto nos primeiros casos da área, que deverão ter confirmação laboratorial, demonstrando-se assim, a importância de seguir as recomendações do serviço de vigilância epidemiológica no tocante a considerar a confirmação clínico-epidemiológica nas áreas com transmissão confirmada. ${ }^{1,5}$

\section{EXAMES DE IMAGEM}

Nos exames de imagem podem ser encontrados achados inespecíficos, compatíveis com artrite com ou sem artropatiaprévia. ${ }^{1}$ 


\section{TRATAMENTO}

Até o momento, não há tratamento antiviral específico para chikungunya. A terapia utilizada é de suporte sintomático, hidratação e repouso. $\mathrm{O}$ tratamento do paciente com suspeita de chikungunya é diferenciado de acordo com a fase da doença: aguda, subaguda ou crônica. ${ }^{1}$

\section{FASE AGUDA}

Como tratamento farmacológico, devem ser utilizados sintomáticos para alívio da dor e da febre, podendo ser a Dipirona e o paracetamol, sendo que o paracetamol deve ser usado com cautela em hepatopatas. As doses de dipirona e paracetamol são as doses padrões recomendadas e utilizadas no tratamento sintomático da Dengue.

Nos casos da dor refratária à dipirona e ao paracetamol, podem ser utilizados os analgésicos opióides como cloridrato de tramadol e codeína. A codeína pode ser associada à dipirona e ao paracetamol nos casos de dor não responsiva à monoterapia.

Os anti-inflamatórios não esteroides (AINEs) não devem ser utilizados na fase aguda da doença, devido à possibilidade de se tratar de uma infecção por Dengue. A aspirina é contraindicada na fase aguda pelo risco de síndrome de Reye e de sangramentos e os corticosteroides são contraindicados na fase aguda.

Como tratamento não farmacológico, recomenda-se a utilização de compressas frias como medida analgésica nas articulações acometidas, de 4 em 4 horas por 20 minutos e hidratação oral dos pacientes ( 2 litros no período de 24 horas). O repouso é considerado fator protetor para evitar evolução para fase subaguda, sendo de extrema importância e devendo ser estimulado.

\section{FASE SUBAGUDA E CRÔNICA}

Para o tratamento farmacológico, pode ser mantida a dipirona como droga de escolha e se, necessário a associação com o cloridrato de tramadol. Pacientes refratários devem utilizar AINEs orais por um período máximo de sete dias.

O uso de corticóides está indicado apenas para os casos com dor articular subaguda e crônica não responsiva a AINEs e analgésicos, em pacientes com dor moderada a intensa, poliarticular, debilitante, assim como em pacientes nos quais haja evidência de processo inflamatório articular, com dor associada a edema. Pode-se iniciar com Prednisona $20 \mathrm{mg} / \mathrm{dia}$ em dose única pela manhã. Interpretar como resposta adequada ao tratamento, a melhora da capacidade para deambular sem ajuda e controle satisfatório das dores.

Neste caso manter a dose até resolução do quadro de dor articular por completo.Em caso de remissão completa da dor, deve-se manter a dose por mais três dias. Caso não haja recidiva do quadro, podese diminuir a dose para $10 \mathrm{mg} /$ dia e aguardar mais três dias, caso a dor não retorne, suspender ao final destes três dias.

A dose inicial poderá ser mantida por até 21 dias, acima deste período, na ausência de resposta, considerar associação de opióides com suspensão ou não do corticoide.

Como medidas não farmacológicas, na etapa em que a dor e o edema começam a regredir, podemos recomendar exercícios ativos,exercícios isométricos, de fortalecimento, de baixo impacto, com objetivo de restabelecer a mobilidade articular e força muscular e evitar a progressão ou instalação de deformidades.

$\mathrm{Na}$ fase crônica, além dos AINEs e do corticoide, pode-se lançar mão da hidroxicloroquina e do metotrexato para controle das manifestações articulares refratárias. Além disso o atendimento deve ser feito, preferencialmente, em unidade de referência com profissionais capacitados para atender pacientes com este perfil. . $^{5,7}$

Apesar de inexistência de estudos de comparação de eficácia entre metotrexato e hidroxicloroquina em chikungunya, optamos por recomendar no tratamento desta fase a hidroxicloroquina como primeira escolha, por seus conhecidos efeitos antinflamatórios no controle da artrite e da dor musculoesquelética potencial ação antiviral, mais principalmente por ser uma droga mais segura quando comparada ao uso de metotrexato. ${ }^{7}$

Para o tratamento da fase crônica da doença, pode ser iniciado a hidroxicloroquina na dose de $6 \mathrm{mg} /$ $\mathrm{kg} /$ dia (dose máxima $600 \mathrm{mg} / \mathrm{dia}$ ) via oral (VO), por um período de seis semanas. Após seis semanas, deve-se reavaliar através da Escala Visual Analógica (EVA), se o paciente estiver sem dor, o tratamento deve ser interrompido. Caso a dor persista, com um EVA menor que 4, o tratamento deve ser mantido por mais seis semanas, podendo ser associado a analgésicos, como sugeridos no protocolo da fase aguda.

Caso a dor persista com a EVA maior que 4, deve-se associar a sulfassalazina $(500 \mathrm{mg})$, dois comprimidos em intervalos de 12/12h, (2g/dia), à hidroxicloroquina por mais seis semanas. Essa combinação mostra-se efetiva no controle dos sintomas 
articulares nos pacientes refratários ao tratamento utilizado anteriormente.

O paciente deverá retornar para avaliação após seis semanas, quando será aplicada a EVA, se o mesmo estiver sem dor, a medicação deverá ser suspensa. Caso a dor persista, com um EVA menor que 4, a associação de hidroxicloroquina e sulfassalazina deverá ser mantida por mais seis semanas.

Se a EVA for maior que 4, a associação deverá ser substituída por metotrexato comprimido de $2,5 \mathrm{mg}$, na dose inicial de $10 \mathrm{mg} / \mathrm{semana} \mathrm{VO}$, podendo progredir até a dose de $25 \mathrm{mg} / \mathrm{semana}$. O ácido fólico deve estar sempre associado na dose de $5 \mathrm{mg}$ semanal, no dia seguinte ao da tomada ao metotrexato.

O paciente deverá retornar após seis semanas. Caso não persista o quadro de dor, a medicação deverá ser suspensa. Se houver persistência do quadro álgico deverá ser encaminhado ao reumatologista para ampliar a investigação diagnóstica.

Efeitos colaterais do metotrexatoncluem: hepatotoxicidade, mielotoxicidade, efeitos gastrointestinais, entre outros. É necessário o ajuste da dose em pacientes com alterações de função renal, sendo contraindicado naqueles com clearence de creatinina menor que $30 \mathrm{ml} / \mathrm{min}$.

Os efeitos colaterais da hidroxicloroquina são principalmente distúrbios visuais, hematológicos, alopecia entre outros. Os pacientes com deficiência de G6PD, insuficiência hepática, porfiria, psoriase, miopatias, e cardiomiopatia apresentam maior risco de efeitos adversos. As lesões devido a toxicidade oftalmológica são raras e relacionadas com o tempo de utilização das drogas e tendem a acontecer após cinco anos de uso da medicação. Recomenda-se a realização de exame oftalmológico inicial e, após cinco anos de uso da medicação, anualmente. Caso esses pacientes possuam fator de risco para maculopatia (tais como insuficiências renal ou hepática) devem realizar exame oftalmológico inicial e anualmente, não aguardando cinco anos para iniciar as avaliações anuais. $^{?}$

Nos casos de chikungunya o tempo de utilização da hidroxicloroquina estará limitada a poucos meses, esperando-se que haja regressão dos sintomas e suspensão da medicação. Porém, para os casos onde o especialista considerar a necessidade de uso prolongado a avaliação oftalmológica deverá ser oferecida dentro do primeiro ano do início da droga e deverá seguir o controle oftalmológicos padrão recomendado após cinco anos. ${ }^{6,7}$

Como medidas não farmacológicas, é necessário evitar atividades que sobrecarreguem as articulações, atividades repetidas, carregar peso e deambular longas distâncias. A utilização das compressas frias deve manter a mesma frequência utilizada na fase aguda e em situações especiais podese utilizar calor. ${ }^{1,5}$

\section{MÉTODOS}

Foi realizado um levantamento bibliográfico utilizando "Chikungunya" e "Manejo clínico" como termos livres. Foram localizados alguns artigos e com alguns livros, foram utilizados como fonte para este estudo.

\section{CONCLUSÃO}

A febre Chikungunya é uma arbovirose, que vem apresentando crescente expansão no Brasil. Possui como principais diagnóstcos diferenciais a Dengue e a Zika, sendo a Dengue uma importante doença endêmica de nosso páis. Todos esses fatores, somados à forma de transmissão através do vetor principal, o Aedes Aegypti, fazem dessa doença um verdadeiro desafio diagnóstico, bem como um importante problema de saúde pública.Quando não identificada precocemente e tratada de forma adequada de acordo com cada forma clínica, pode evoluir com importante progressão para manifestações articulares incapacitantes, logo, é importante realizar um diagnóstico precoce e um tratamento adequado, de acordo com as normas do Ministério da Saúde e grandes Centros de Referência, para que se possadiminuir cada vez mais as taxas de mortalidade e principalmente de morbidade desta importante $\mathrm{e}$ emergente doença.

\section{REFERÊNCIAS BIBLIOGRÁFICAS}

1. Dengue, Zika e Chikungunya, Diagnóstico Tratamento e Prevenção - 1ªEdição - Rio de Janeiro. Ed. Rubio, 2016.

2. Donalisio Maria Rita, Freitas André Ricardo Ribas. Chikungunya no Brasil: um desafio emergente. Rev. bras. Epidemiol, v.18(1):283-285, 2015. 
3. Gérardin, P. et al. Multidisciplinary Prospective Study of Mother-to-Child Chikungunya Virus Infections on the Island of La Réunion. PLoS Med., v.5, n.3, p.60, 2008.

4. Lenglet, Y. et al. Chikungunya infection in pregnancy: evidence for intrauterine infection in pregnant women and vertical transmission in the parturient. Survey of the Reunion Island outbreak. Journal de GynécologieObstétriqueetBiologie de la reproduction, Paris, v.35, n. 6, p. 578-583, 2006.

5. Ministério da Saúde. Secretaria de Vigilância em Saúde. Departamento de Vigilância das Doenças Transmissíveis. Febre de chikungunya: manejo clínico / Ministério da Saúde, Secretaria de Vigilância em Saúde, Secretaria de Atenção Básica. Brasília: Ministério da Saúde, 2015.

6. Ministério da Saúde. Secretaria de Vigilância em Saúde. Departamento de Vigilância das Doenças Transmissíveis. Preparação e resposta à introdução do vírus Chikungunya no Brasil. Brasília, 2014.

7. Brito Carlos Alexandre Antunes de, Sohsten Ana Karla Arraes von, Leitão Clezio Cordeiro de Sá, Brito Rita de Cássia Coelho Moraes de, Valadares Lilian David De Azevedo, Fonte Caroline Araújo Magnata da et al . Pharmacologic management of pain in patients with Chikungunya: a guideline. Rev. Soc. Bras. Med. Trop., v.49(6):668-679, 2016.

\title{
APENDICE 1
}

\section{IPC AMBULATÓRIO INTERDISCIPLINAR DO HPC}

\section{ENTREVISTA}

Data da entrevista:

Idade da criança:

Grau de parentesco:

\author{
Iniciais do Entrevistado:
}

Idade da entrevistada: ( ) 18 a 28 anos ( ) 29 a $39 \operatorname{anos~(~)~} 40$ a 50 anos ( ) mais de 50 anos

É responsável pela manutenção do lar? ( ) sim ( ) não

Renda familiar aproximada: ( ) 1 salário mínimo ( )2 salários mínimos ( )3 ou mais salários mínimos

1) Quais foram os primeiros indícios que havia algo diferenciado no desenvolvimento do seu filho?

a) Com que idade estava a criança neste momento?

b) Quem observou essas alterações no desenvolvimento da criança (escola, babá, avó, pais etc)?

2) Através dessas observações sobre o comportamento e desenvolvimento, qual foi a reação da família?

a) Que providências foram tomadas?

3) Procuraram um profissional de saúde?

a) Qual?

b) Houve diagnóstico de imediato? ( ) Sim （ ) Não

c) Com que idade a criança obteve o diagnóstico?

d) Qual profissional fez o diagnóstico de TEA?

4) Qual foi o tratamento recomendado?

a) Quando iniciou?

b) Há quanto tempo a criança está emtratamento neste Serviço?

5) Qual a sua avaliação sobre as mudanças observadas no comportamento e no desenvolvimento após o tratamento?

6. Qual é a sua maior preocupação em relação ao seu filho/neto? 